\title{
The Role of Multimodality and Technology in Teaching EFL to Visually Impaired Lower-Level Learners
}

\author{
Astanina Anna', Boltenkova Yuliya ${ }^{2}$, Rassakazova Tatiana ${ }^{3}$ \\ 1 Ural Federal University, Ekaterinburg, Russia \\ ${ }^{2}$ Ural Federal University, Ekaterinburg, Russia \\ ${ }^{3}$ Ural Federal University, Ekaterinburg, Russia \\ Corresponding author:Tatiana Rassakazova, trasska@mail.ru
}

\begin{abstract}
The era of postliteracy suggests development of language proficiency in multimodal ways creating equal opportunities for all learners including those with disabilities. Despite contemporary technological advances, certain special needs, such as blindness, make most online courses difficult to access. We propose a set of presuppositions and principles behind online EFL course development for blind and visually impaired learners, which are based on the multimodal nature of input during language learning and teaching of blind people to activate other senses during this process. The preliminary results of the study based on empirical data are to be published shortly.
\end{abstract}

Keywords: blind language learners, EFL for blind learners, multimodality in teaching the blind

\section{Introduction}

Foreign language proficiency at different levels is viewed nowadays as an indispensable skill. Not only is foreign language an obligatory subject worldwide, but it is also a tool that helps at work and in recreational activities. English, being the modern lingua franca, plays worldwide a social role which is impossible to overestimate. Today having mastered English means having unhindered independent access to a whole range of political, economic, cultural and scientific resources, thus being able to be free in terms of judgement, mentality and way of life. The era of postliteracy is the time of free choice, the epoque of multilingualism and a multicultural world, embracing the idea of equal access to information and the concept of self-study life-long learning. Multilingualism being "a direct indicator of cultural and social wealth" [Yaman, 2015, 769], many countries spend much time, effort and money trying to provide their citizens access to modern language education. 
What is more, the ever-present Internet makes various distant courses and educational mobile applications easily accessible and largely used worldwide, narrowing the so-called digital divide [Hinnant, 2004, 851] year after year.

Yet, despite all the success, there is a very distinct social group feeling the digital gap being still very deep. Unfortunately, the blind and visually impaired often feel excluded and discriminated against in terms of wide access to distant self-study educational materials, thus being unable to fully embrace the postliteracy epoch tendency to self-directed education and, as a result, risking becoming less employable in the nearest future [Viner et al, 2016, 61]. It seems obvious that "reducing the digital divides may only be achieved by improving $\langle\ldots\rangle$ educational opportunities for the public at large" [Hinnant, 2004, 852].

According to the concept of inclusive education that promotes the principles of education for all [Opertti, 459], teachers are challenged to find the ways to "meet diverse learners' needs [Ibidem., 459]. Technological advances have proved their effectiveness in creating an inclusive environment for teaching foreign languages to learners with special needs in classrooms. However, contemporary classrooms are gradually becoming digital, substituting "live" offline mode of learning for an online mode. It goes without saying that there must be certain principles underlying the choice of material as well as its presentation to the learners with special needs that could be helpful in organising online activities of such learners and later might become the basis for a full self-study online course.

Teaching foreign languages to learners with various impairments, one must combine the knowledge of language itself, methodological principles, and the knowledge of specialised psychology and pedagogics. The problem is that in most cases teachers lack knowledge of special techniques to deal with the blind and have to use "trial and error method... and their intuition" [Kocyigit and Artar, 2015, 693]. In our study we are going to summarise the research and experience of working with $t$ blind learners and propose certain principles to develop and adapt EFL materials for an online selfstudy course.

\section{Methods and Materials in teaching the visually impaired}

When it comes to blind learners, face-to face teaching methods and techniques are widely used globally and have undoubtedly proved to be a success. As a result, there is nowadays no argument about the fact that 
"blind learners display the same aptitude for learning foreign languages as their sighted counterparts. $\langle\ldots\rangle$ When blindness does not compound with other factors, there should not be any difficulties in language acquisition. Therefore, it is possible for a blind learner to acquire successfully $\langle\ldots\rangle$ a foreign language" [Jedynak, 2011, 269, 272].

The existing experience of teaching foreign languages to the blind provides enough information to point out some distinct traits of the blind learner profile. To start with, complete sight loss very often "results in the easiness of concentration and well-developed analytical skills" [Ibidem, 269]. What is more, the blind tend to develop additional aural sensitivity, enabling them "to acquire specific phonetics $\langle\ldots\rangle$ of a foreign language only by ear, without any formal instruction concerning the pronunciation of particular sounds" [Ibidem, 272]. Being naturally predisposed, the blind are usually "more aware and responsive to the melody of a foreign language, i. e. its rhythm, stress and intonation patterns" [Ibidem, 271], thus they appear to be able to effortlessly acquire a native-speaker accent in a very short time. Incredibly high memory efficiency of the blind is also widely recognized [Czerwínska and Piskorska, 2018, 216]. Last, but not least, the blind tend to mostly have a very positive attitude towards discovering new things, obtaining new skills, "learning something new and exciting, different from a familiar $\langle\ldots\rangle$ environment" [Jedynak, 2011, 272]. They seem to have a certain craving for the new knowledge and skill, which seems to be highly motivating on the long path to mastering a foreign language. Unfortunately, it is necessary to point out that "there is a high risk of verbalism among the blind, i. e. using information stored in memory without being able to link the information to any kind of direct sensory experience" [Czerwínska and Piskorska, 2018, 216].

Anyone designing a course for the blind and visually impaired, should take into consideration both the learners' advantages and disadvantages, the impact of fragmentary images, difficulties in acquiring natural concepts and the risk of verbalism included [Ibidem, 2018, 217]. However different the blind learners are from their sighted peers, whatever specific routes they tend to choose on their way to acquire a foreign language, both the blind and the sighted share the need for autonomous behaviour and the urge for self-directed and self-paced learning. 


\section{CALL in teaching the visually impaired}

Here comes "the posh term "Computer-Assisted Language Learning (CALL)" [Yaman, 2015, 770] which "puts a strong emphasis on this autonomy dimension with the direct reference of learning instead of teaching" [Ibidem].

Assistive technologies such as screen readers, Braille displays and keyboards, voice-to-text converters "can be attributed as a breakthrough to <... > information" [Kamali Arslantaş, 2017, 101] for visually impaired people. They definitely play a crucial role in the current revolutionary changes in education for the blind, making the learning process more accessible, more "efficient, attractive, interactive and dynamic" [Isalia, 2014, 2192]. However, in spite of a wide range of assistive technologies available to the blind nowadays, the foreign language educational community is still striving to create a selfstudy distant course, able to fulfill all of their special needs.

The Before-MOOC era was distinguished in 2009-2012 by a set of shortlived experimental interactive distant courses - ELLVIS, VET4VIP, etc. stemming from the Socrates ALLVIP project. The latter combined for the first time ever a screen reader for audio messages, a tactile screen interface, headphones with 3-D sound and a haptic force-back joystick in order to provide life-like experience while focusing on the oral language, listening comprehension and pronunciation alongside with various practice tasks and exercises [Deharde, 2010, 3]. As to our knowledge, the ALLVIP-family projects were all closed around 2012, claiming to be successful but leaving more questions than answers alongside with a certain amount of interesting technical and pedagogical ideas and presuppositions to be further investigated. MOOCs started spreading worldwide circa 2012, some of them trying to gain advantage by using some of the ALLVIP-like principles (such as screen-readers extensive usage for example) [Marques et al., 2019, 103].

Massive Open Online Courses (MOOCs) have become widespread nowadays. They definitely possess a great number of positive features that make them popular all over the world. Designed to promote freely available, open access, high quality learning opportunities to all, they teach learners to self-regulate their learning process involving learners' context to motivate, self-regulate and achieve higher results [Hood et al., 2015, 90]. Most MOOCs started as free of charge products, giving people an opportunity to learn anything anywhere. With growing popularity of this method, many universities took it on board and established whole degree studies. Today, there are several universities providing educational services but existing 
only in online format, with no "material" representation of objects or people connected with them.

MOOCs are not flawless tools, though. To complete a course one must be a motivated individual, able to work individually and independently. Researchers from Portugal and the USA have presented data showing that less than 5 percent of low-level learners of a foreign language via MOOC exhibit necessary readiness and are highly determined to learn [Agonacs et al., 2020, 1175]. A research by Hew and Cheung presented additional data on the learners' and teachers' perspectives of using MOOCs. Enrolling to a MOOC, students wish to "refresh some information ... or are curious" about working in such a way, resulting in "mixed attitudes" [Hew and Cheung, 2014, 47]. Teachers also cannot agree on the point of using MOOCs. On the one hand, the popularity of such courses is enormous, course developers are altruists ready to provide top quality content for free and develop online pedagogical techniques which are highly motivating. On the other hand, the level of instruction is sometimes inferior to that provided in class, and the amount of time and energy necessary to develop and later maintain and renew a course as well as check feedback and learners' writing is immense, whereas the whole course may not be successful or popular, or become "no more than a line in a teacher's portfolio" [Ibidem, 49-51].

Today each institution considers implementing MOOCs a necessity to be competitive in the sphere of education. However, when it comes to teaching people with special needs, there arise a number of issues that need to be addressed to meet the needs of people with impairments. "A key concern is that $<\ldots>$ individuals accountable for supporting and implementing e-learning within postsecondary institutions, in the rush to integrate technology into teaching fail to think about the accessibility needs of students with various disabilities" [Fichten et al., 2009, 242]. In this respect, individuals with visual impairments and particularly the blind are mostly disadvantaged, as the very idea of MOOCs is to promote learning through various channels, most of which the blind do not perceive. A survey conducted in the higher education institutions of Slovenia, Portugal, Italy and Sweden witnessed that all blind and visually impaired students acknowledge the need for adaptation of learning materials at least to some extent and "more than 50 percent among the blind need total adaptation of learning materials for successful following up the study course" [Gaps and Needs Analysis, 2016, 45]. To make matters worse, there are subjects that are particularly hard for the blind learn- 
ers to cope with. Such subjects feature a high percentage of abstract ideas. To name a few highly abstract subjects that are problematic to implement without a regular "human" guidance and support in learning, one would turn to mathematics, philosophy and foreign languages.

However, according to cognitive studies, mastering a foreign language by a blind person should not be supposed to be an unachievable goal [Czerwínska and Piskorska, 2018, 220]: "although blindness affects perception, it does not obstruct linguistic and verbal development. The only reason for the lack of success in foreign language learning may be due to the inadequate support and encouragement from the environment" [Jedynak, 2011, 270].

\section{Results and discussions}

The background research into the development of MOOCs for EFL blind learners brought to light the complexity of the task. In an attempt to develop an online course for blind low-level, especially beginner, learners, we took into account the following presuppositions and principles.

1. Multimodal way of presenting information

There is a common misconception that blind learners are helpless when it comes to dealing with digital devices. Contrary to this idea, learners with special needs are active Internet-users and gadget-users. Not only do contemporary devices and software allow blind learners to perceive information with the help of screen reading programmes, they also let them navigate through web pages by reading the content of the page aloud. There are special features of such programmes that the users are aware of but material designers do not take into account due to lack of knowledge on these features. For example, a special mode of presenting information (e.g. capitalisation of a word with periods after each letter) will make the software reader spell the word.

The point of criticism for MOOCs is poor adaptation of material presentation for the learners with special needs. Typical ways of making a course interactive fail when the designers realise limitations imposed: limited number of task types, inability to visualise, difficulty to describe some phenomena (e.g. colour), etc. To make matters worse, complete beginners might get stressed when given a lot of material to read with the help of screen-readers. This brings us to the idea of multimodal ways of presenting information. We consider it necessary to introduce the course materials in (at least) two ways: audio and screen-reader-friendly. By providing audio we focus the learners on pronunciation and create an illusion of a real presenter talking to a learner in conversa- 
tional style, thus reducing the stress. What is more, both the accessible scientific data [Kamali Arslantaş, 2017, 101] and our own research witnessed a very strong preference given by the blind to the auditory input compared to reading either via Braille or with the help of screen-reader software. Researchers point out that the speaking/listening mode is the most logical, acceptable and natural way to interact and has proved to be "a successful means of conveying information to the mass"..."only audio can reproduce authentic aural stimuli, the two most common being spoken words and music". [Moloo, et al., 2018, 103-104]. When teaching visually impaired learners online, firstly the presentation of information in such a way helps to develop awareness of pronunciation features in the target language (intonation, sounds, cohesion, etc.).

Research held by a group of Chinese scientists [Lin, et al., 2020, 9] suggests that conversational style of material delivery positively affects material retention. Besides, "if the learning material directly addresses the learners, they may feel that learning is more relevant to themselves and thus invest more mental effort in learning the material" [Ibidem]. Blind learners may feel disadvantaged when beginning to learn a foreign language, so a presenter who explains material in a friendly conversational way, addressing the learner, might help to decrease stress.

The second mode of information provision, i. e. screen-reader adapted, partially replicates the material presented in the audio file, focusing students' attention on the spelling of the words and some extra features such as grammar, word order, cultural differences, etc. By providing the second presentation of the same lexical units or grammar we shift the focus from the pronunciation and the meaning of the word or structure to the form and function, which corresponds to the methodological principle of communicative method teaching. The same sequence of teaching language units (hear- speak - read- write) is described by Lewis and Hill [Lewis, 1992, 31].

It is also worth noticing that the screen-reader friendly part of the course can be easily transformed into Braille display-friendly text, enabling those who prefer reading Braille to do so. Braille displays being a rather expensive commodity and a significant part of the blind having quite a controversial attitude towards the Braille reading, we do not perceive Braille as a crucial integral part of the course, relying more on screen-reader software instead. Anyway, we find it necessary to provide our students with as many multimodal ways of obtaining and processing the course materials as possible. The ability not only to orally communicate but also to read and write in En- 
glish being a must, we see the screen-reader-/ Braille display- friendly part of the course as an additional opportunity for the students to practice their reading skills either via Braille display or with the help of screen-reader software. It comes in accordance with the CALL and typhlopedagogy specialists' point of view [Belova, 2017; Kapperman et al., 2018].

\section{Clear consistent instructions}

It is true that successful task completion lies in the correct instruction. Typically, learners might try to guess what they are required to do in this or that task, skipping reading the instruction provided. It does not work with blind learners who perceive instruction as a part of the task. Instructions precede the exercises and are either given by the course presenter or read by the screen-reader. Therefore, they must be short, clear and contain enough detail. Care must be taken not to overcomplicate the instructions with high-level constructions which will hinder task understanding rather than make it clear. Moreover, instructions should be consistent enough to help learners navigate through the course. In the EFL course developed for the learners with visual impairment the number of task types will be rather limited. At first, it might take the learners some time to familiarise themselves with the instructions and the way tasks should be completed. Later on the course such instructions will be those necessary stepping stones for the learners to rely on. We suppose that learners will benefit from small tips to approach task completion in the instructions. If the task is changed or modified, so must the instruction. It is easier to add several points to the familiar instruction than invent a completely new one. Tips to help the learner approach the task may be given as a separate sentence after the familiar instruction. By doing this and repeating the instructions with the tips we build background knowledge of strategies which will be helpful for the course-takers.

Instructions should be provided to the course navigation as well as to the tasks. Not all the learners may exhibit outstanding computer skills. The task will be twice as complex since the course-taker cannot see. Engaging course content and activities will work better if the instructions for navigating the course itself are clear as well, even for the learners without special needs [Agonacs et al., 2020, 1175]. In other words, we help to promote learner's autonomy, so necessary for successful MOOC completion.

3. Teaching in L1

A learner's mother tongue cannot be eliminated from EFL teaching lower-level blind learners in an online course. At present, the communicative 
approach is considered to be the best to teach a foreign language. Traditional implementation of this method suggests using as little of learners' first language as possible. This approach, however, does not work in a situation when a blind learner sits in front of a computer screen in order to learn the basics of a foreign language. Such learners need support more than any other group of people. Positive emotions, manageable tasks, situation of success together with reasonable explanation and material presentation in the learner's mother tongue constitute the basis of a motivating environment in an online course. A course-taker might struggle with typing, another system of coding information, new grammar, new words, intonation, etc., that is why it is particularly important to create a motivating background and introduce new elements gradually, few at a time, making strong correlation between a word and its image (whatever kind of it a learner might have) and its translation in the native language.

The grammar-translation method is not a failing way to teach. It brings us to different results but it would be incorrect not to take into account the benefits of using such a method of teaching. Providing background explanation in the L1 we help the learner focus on what they know, using familiar terms in the language they are proficient at. This is of utmost importance to the blind lower-level learners: they learn a word, a phrase, and by using the most straightforward way to understand the meaning make them a part of their learning experience to later rely on. Besides, this method is rather traditional and favoured by the blind [Belova, 2017, 592].

4. Practical tasks

Motivation plays a key role in any learning. When developing a course, designers strive for making the course engaging for the learner by using bright pictures, interest-provoking topics, cultural phenomena, etc. Unfortunately, all these tips do not work for the blind. One of the ways to engage the learner, especially a lower-level learner, into the course is to set real-life tasks and demonstrate the way to act in such situations. By making the tasks serious and realistic, we teach learners to face regular contexts and deal with real-life situations in English. We strongly believe that mastering the foreign language by our students is the most obvious, but certainly not the only aim as the course designers. To raise our students' self-esteem and self-confidence, to help them become more independent, more able, more self-sufficient in the reality of postliteracy era - that is the aim of equal importance for us, the authors. 


\section{Conclusions}

In the period of postliteracy, with the development of technologies, there appear new ways of addressing complicated issues of teaching learners with special needs. Technological advances can be helpful for blind learners to get access to the courses, including MOOCs, provided that the materials presented are adapted to allow the course to be followed effortlessly in terms of the course structure and accessibility. Traditional ways of teaching are applicable and might be rather effective in helping learners to achieve language proficiency at least at lower levels. A number of principles proposed in the article aim to develop learners' autonomy in learning a foreign language and help MOOC designers of EFL courses adapt the materials.

\section{Funding:}

This research was financially supported by the Russian Foundation for Basic Research (Grant No. 17-29-09136/20 "Multilingualism in the era of post-literacy: Philosophical and cultural studies and methodological and pedagogical development of a multilingual education model”).

\section{Conflict of Interest}

The authors have no conflict of interest to declare.

\section{References:}

1. Yaman. Digital divide within the context of language and foreign language teaching. Procedia - Social and Behavioral Sciences, 176 (2015), pp. 766-771, 10.1016/j.sbspro.2015.01.538

2. C.C. Hinnant. Review of Virtual Inequality: Beyond the Digital Divide by Karen Mossberger, Caroline J. Tolbert and Mary Stansbury. Perspectives on Politics, Vol. 2, № 4 (2004), pp. 851-852, http://jstor.org/stable/3688574 (Accessed 22 August 2020).

3. M. Viner, E. Gardner, M. F. Shaughnessy, C. J. Bonk, M. M. Lee, T. C. Reeves, T. H. Reynolds. Interview with Curtis J. Bonk, Mimi Miyoung Lee, Thomas C. Reeves and Thomas H. Reynolds. Educational Technology, vol. 56, № 4 (2016), pp. 59-646 http://jstor.com/stable/44430482 (Accessed 22 August 2020).

4. R. Opertti, J. Brady. Developing inclusive teachers from an inclusive curricular perspective. Prospects 41 (2011), pp. 459-472, doi:10.1007/s11125-011-9205-7

5. N. Kocyigit, P.S. Artar. A challenge: Teaching English to visually-impaired learners. Procedia — Social and Behavioral Sciences 199 (2015), pp. 689-694. doi: 10.1016/j.sbspro.2015.07.599. 
6. M. Jedynak. Across the borders of typhlopedagogy and SLA: new research problems, recent findings, perspectives: M. Pawlak (editor) Extending the Boundaries of Research on Second Language Learning and Teaching. Springer (2011), ISBN 978-3-642-20140-0

7. K. Czerwínska, A. Piskorska. Cognitive functioning of a blind student in a foreign language classroom. Forum Pedagogiczne, vol. 8, issue 2 (2018), pp. 211226, www.cejsh.icm.edu.pl/cejsh/element/bwmeta1.element.ojs-doi-10_21697_ fp_2018_2_15 (Accessed 01 August 2020).

8. T. Kamali Aslantaş. Foreign language education of visually impaired individuals: a review of pervasive studies. Ihlara Eğitim Araştırmaları Dergisi, vol. 2, issue 2 (2017), pp. 95-104, https://dergipark.org.tr/en/pub/ihead/issue/33690/373505 (Accessed 3 August 2020).

9. N. Isalia. The assistive software, useful and necessary tool for blind students' abilities development. Procedia - Social and Behavioral Sciences, 116 (2014), pp. 2189-2192, 10.1016/j.sbspro.2014.01.541.

10. T. Deharde. Accessible Language Learning for Visually Impaired People, http://conference.pixelonline.net/ICT4ALL2010/common/download/Proceedings_ pdf/IBL55_Deharde.pdf (Accessed 19 June 2020).

11. B. P. Marques, P. Escudeiro, A. Barata, P. Carvalho, A. de Sousa, P. Queirós. Assistive Technology Applied in an Inclusive MOOC for the blind. Proceedings of the 11th International Conference on Computer Supported Education (CSEDU 2019), vol. 1, ISBN: 978-989-758-367-4, pp. 100-110, 10.5220/0007724901000110.

12. N. Hood, A. Littlejohn, C. Milligan. Context counts: How learners' contexts influence learning in a MOOC. Computers \& Education 91 (2015), pp. 83-91, dx.doi. org/10.1016/j.compedu.2015.10.019

13. N. Agonács, J. F. Matos, D. Bartalesi-Graf, D. N. O’Steen. Are you ready? Self-determined learning readiness of language MOOC learners. Education and Information Technologies 25 (2020), pp. 1161-1179, doi.org/10.1007/s10639-019-10017-1.

14. K. F. Hew, W. S. Cheung. Students' and instructors' use of massive open online courses (MOOCs): Motivations and challenges. Review. Educational Research Review 12 (2014) pp. 45-58. /dx.doi.org/10.1016/j.edurev.2014.05.001

15. C.S. Fichten, V. Ferraro, J. V. Asuncion, C. Chwojka, M. Barill, M. N. Nguen, R. Klomp, J. Wolforth. Disabilities and e-learning problems and solutions: and exploratory study. Educational Technology and Society: New Directions in Advanced Learning Technologies, vol. 12, № 4, pp. 241-256, http://jstor.org/stable/10/2307/ jeductechsoci.12.4.241 (Accessed 22 August 2020). 
16. Gaps and Needs Analysis: European Report and Roadmap (2016), ISBN 978-972-674-778-9, https://repositorioaberto.uab.pt/handle/10400.2/5980 (Accessed 5 August 2020).

17. R. K. Moloo, K. K. Khedo, T. V. Prabhakar. Critical evaluation of existing audio learning systems using a proposed TOL model. Computers and Education, 117 (2018), pp. 102-115, doi.org/10.1016/j.compedu.2017.10.004

18. L. Lin, P. Ginns, T. Wang, P. Zhang. Using a pedagogical agent to deliver conversational style instruction: What benefits you can obtain? Computers and Education, 143 (2020), pp. 1-9, doi.org/10.1016/j.compedu.2019.103658

19. M. Lewis, J. Hill. Practical techniques for language teaching. 4th ed. Hove, England. Language Teaching Publications (1992), pp. 136.

20. G. Kapperman, E. Koster, R. Burman. The study of foreign languages by students who are blind using the JAWS screen reader and a refreshable Braille display. Journal of Visual Impairment and Blindness, vol. 112, issue 3 (2018), pp. 317-323, $10.1177 / 0145482 \times 1811200312$

21. T. Belova. Accessible language: Foreign language teaching strategies for blind and visually impaired students. Advances in Social Science, Education and Humanities Research, vol. 144 (2017), pp. 592-596, http://atlantis-press.com/proceedings/ icadce-17/25881385 (Accessed 19 August 2020).

DOI 10.15826/B978-5-7996-3081-2.14

\title{
Assessment Cultures and Virtual L2 Teaching and Learning
}

\author{
Leontjev Dmitri', Rasskazova Tatiana ${ }^{2}$ \\ ${ }^{1}$ University of Jyväskylä, Jyväskylä, Finland \\ 2 Ural Federal University, Ekaterinburg, Russia; \\ University of Jyväskylä, Jyväskylä, Finland \\ Corresponding author:Tatiana Rassakazova, trasska@mail.ru
}

Abstract. The unprecedented emergency remote teaching [Hodges et al., 2020] has created unique challenges, with educators facing higher demands placed on them as they have to assure quality teaching, learning, and assessment 